\title{
Assessment of high enthalpy flow conditions for re-entry aerothermodynamics in the plasma wind tunnel facilities at IRS
}

\author{
Stefan Loehle ${ }^{1}$ (1) $\cdot$ Fabian Zander $^{2} \cdot$ Martin Eberhart $^{1} \cdot$ Tobias Hermann $^{3} \cdot$ Arne Meindl $^{1}$. \\ Bartomeu Massuti-Ballester ${ }^{4}$. David Leiser ${ }^{1} \cdot$ Fabian Hufgard $^{1} \cdot$ Adam S. Pagan $^{5} \cdot$ Georg Herdrich $^{5}$. \\ Stefanos Fasoulas ${ }^{5}$
}

Received: 26 April 2021 / Revised: 7 October 2021 / Accepted: 8 October 2021 / Published online: 1 November 2021

(c) The Author(s) 2021

\begin{abstract}
This article presents the full operational experimental capabilities of the plasma wind tunnel facilities at the Institute of Space Systems at the University of Stuttgart. The simulation of the aerothermodynamic environment experienced by vehicles entering the atmosphere of Earth is attempted using three different facilities. Utilizing the three different facilities, the recent improvements enable a unique range of flow conditions in relation to other known facilities. Recent performance optimisations are highlighted in this article. Based on the experimental conditions demonstrated a corresponding flight scenario is derived using a ground-to-flight extrapolation approach based on local mass-specific enthalpy, total pressure and boundary layer edge velocity gradient. This shows that the three facilities cover the challenging parts of the aerothermodynamics along the entry trajectory from Low Earth Orbit. Furthermore, the more challenging conditions arising during interplanetary return at altitudes above $70 \mathrm{~km}$ are as well covered.
\end{abstract}

Keywords Space transportation $\cdot$ High enthalpy flow fields $\cdot$ Aerothermodynamics

\section{Introduction}

State-of-the-art experimental investigations of atmospheric entry flight are conducted using impulse facilities or plasma wind tunnels [36]. A survey by Smith et al. from 1997 lists the plasma facility developments for aerospace applications

Stefan Loehle

loehle@irs.uni-stuttgart.de

Fabian Zander

fabian.zander@usq.edu.au

Martin Eberhart

loehle@irs.uni-stuttgart.de

Tobias Hermann

tobias.hermann@eng.ox.ac.uk

Arne Meindl

meindl@irs.uni-stuttgart.de

Bartomeu Massuti-Ballester

bartomeu.massuti@gmail.com

David Leiser

dleiser@irs.uni-stuttgart.de

Fabian Hufgard

hufgard@irs.uni-stuttgart.de until the end of the last century [49]. The European facilities have been integrated in that article already, e.g. the facilities at the German Research Center (DLR) and the French facilities in Bordeaux. Figure 1 shows an extension of this plot taking into account new developments in, e.g. China and Italy. For example, these new developments include the 


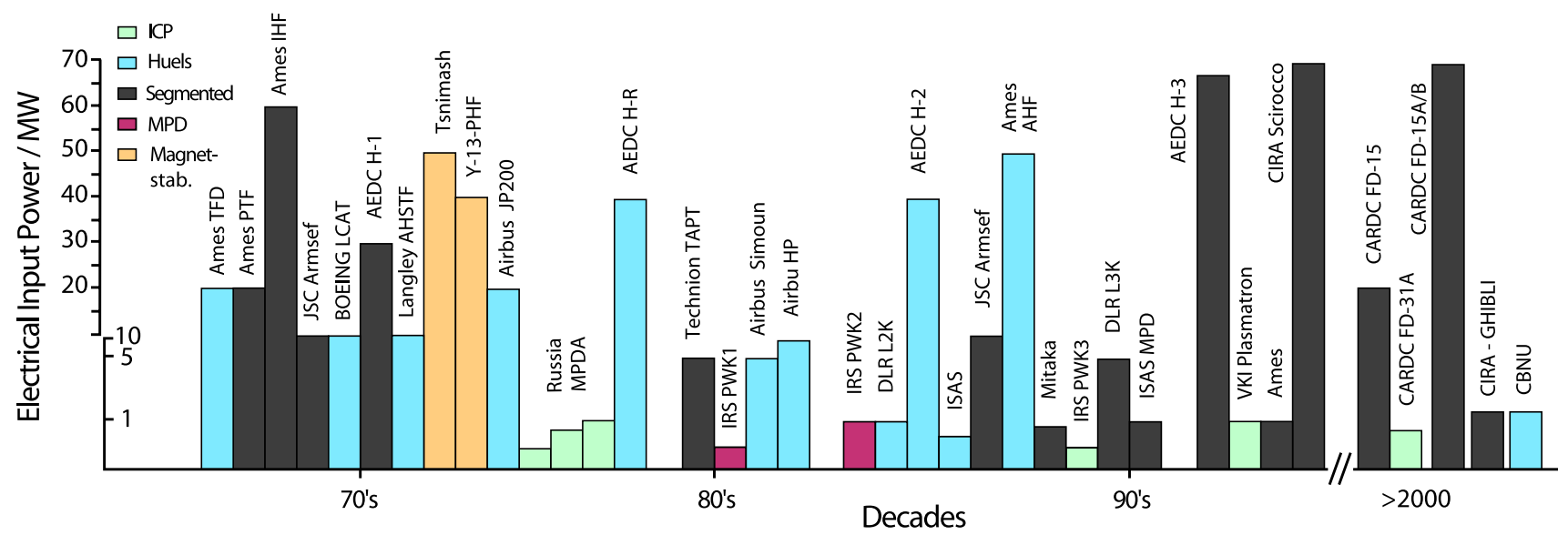

Fig. 1 Aerospace plasma facility development until the late 1990s (reproduced from Smith et al. [49]) and additional facilities developed more recently [46] (Ames: NASA Ames Research Center, JSC: NASA Johnson Space Center, LCAT: Boeing Large Core Arcjet Tunnel,AEDC: Arnold Engineering Development Center, Langley:
NASA Langley, Technion: Technion Wind Tunnel Complex, Israel, DLR: German Aerospace Center, Mitaka: Jaxa Mitaka Wind Tunnel, Tokyo, VKI: Van Karman Institute, Belgium, CARDC: China Aerospace Research and Development Center, CIRA: Italian Aerospace Research Center, CBNU: Chonbuk National University, Korea) consolidation of NASA's arcjet capabilities at NASA Ames Research Center for the development of the Orion capsule for manned space missions [9]. For such large spacecraft as well as for the return of smaller capsules from interplanetary missions at high speeds, testing environments taking into account radiative heating are required [48]. Radiative heating capabilities were installed in the arcjet facilities at NASA Ames through a setup for additional laser heating during plasma testing [12]. At the Italian research Center CIRA, besides the Scirroco facility, a smaller constricted arcjet named Ghibli is operational since 2007 [46]. Similarly, the Chonbuk National University operates a $2.5 \mathrm{MW}$ constricted arcjet facility in Jeonju, Korea since 2015 [27]. New arcjet facilities have also been developed at the China Aerodynamics Research and Development Center (CARDC) in Mianyang, China. Here, the Hypervelocity Aerodynamics Institute installed two large segmented arcjets and a $1 \mathrm{MW}$ inductively heated source.

New plasma generator developments were mainly driven by the requirements for higher enthalpy levels and higher total pressures for atmospheric entry from interplanetary travel. The approximate operational capabilities of the various generators are depicted in Fig. 2. However, this graph is not plotted based on actual measurement data.

In the following, we only present measured flow conditions to provide a profound base for the performance of the facilities. This paper focuses on the presentation of the recent performance analysis of the facilities developed at the Institute of Space Systems (IRS) and the associated capabilities for the investigation of entry manoeuvres in the atmospheres of Earth. The next section provides the background information about the heritage of the facilities

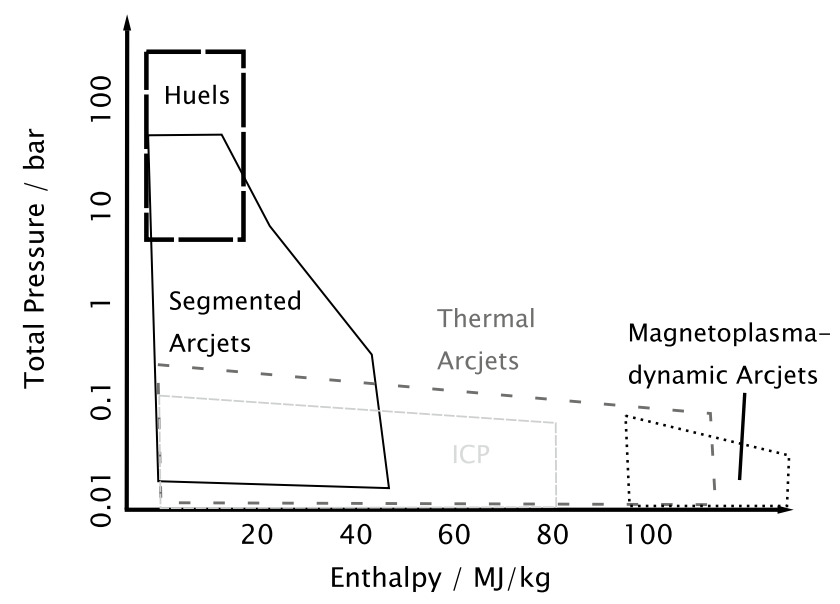

Fig. 2 Illustration of the operational capabilities for different generator principles for air conditions (similar to Fig. 1 in Smith et al. [49])

and new features. Afterwards, each facility is presented with its operational range and specific features. The operational range is defined as the range of total pressures and heat fluxes achievable on a $50 \mathrm{~mm}$ diameter flat faced cylinder with an edge radius of $11.5 \mathrm{~mm}$. In Europe, this geometry is a standard probe geometry which was established by ESA during the European Hermes project [15]. Various heat flux measurement methods have been developed and applied worldwide over the years [32]. All heat fluxes presented throughout this paper have been measured using a water-cooled calorimeter to determine the copper cold wall heat flux. The flow conditions are categorised with respect to actual flight trajectories resulting in a performance map based on experimental data sets. 


\section{Background}

Plasma wind tunnels have been developed to simulate the heat load which a candidate material would have to withstand during atmospheric entry $[29,36]$. The flow fields provide the main aerothermodynamic features of a high enthalpy re-entry flow. Depending on the requirements for the simulation of a certain condition on the trajectory, a flow condition is adjusted, which might be super- or subsonic. For the characterisation of superorbital entry, the simulation of the stagnation streamline is achieved by a subsonic flowfield. The supersonic flow conditions are required for testing of complex shapes as for example for re-entry break-up analysis. Here, the shock interaction with the structure is required for useful ground testing. The challenge for all facilities is that the plasma is generated through a different mechanism than the shock compression induced plasma experienced in flight. Therefore, this environment has to be carefully adjusted and experimentally quantified to achieve conditions comparable to the main features of the real re-entry flight scenario. This approach motivates the requirement for the thorough investigation of the local mass-specific enthalpy, chemical composition, radiative and convective heating as well as surface chemistry effects.

The development of plasma wind tunnels at the Institute of Space Systems (IRS) of the University of Stuttgart was initiated and triggered by a German-French research program for the development of a space transportation system called Hermes in the 1980s [3]. Since then, further developments and improvements led to facilities which provide high enthalpy plasma flows for fundamental thermal protection material testing foreseen for entry maneuvers into the atmospheres of Earth, Mars, Venus and Titan [8, 17, 21]. Although originally the focus was laid on the simulation of conditions for a return from low Earth orbit, i.e. low Earth orbital flight velocities, it is shown in this paper that the facility capabilities also allow for the simulation of superorbital re-entry trajectory conditions leading to surface heat fluxes exceeding $10 \mathrm{MW} / \mathrm{m}^{2}$ [16].

There are three generator designs in use at IRS: Two arc-heated generators and one inductively heated plasma source (ICP). From the perspective of a typical re-entry trajectory, the magnetoplasmadynamic generator RD5 was developed for the upper part of the atmosphere and the beginning of the re-entry and is mounted in PWK1 or PWK2 [8]. The design is based on the know-how at the institute for high power electric space propulsion systems [6]. It provides particularly high enthalpies. The limiting factor are the attainable total pressure. For lower altitudes, and hence higher pressures, the thermal arc-heated generator RB3 is utilised (mounted in PWK4). It is a classical thermal arcjet with an advanced design for higher total pressures, but at lower enthalpies compared to RD5. The inductively heated source IPG3, used in PWK3, was developed for more fundamental research on aerothermochemistry which is relevant at all trajectory points for a reentry [7, 19]. The main advantage of this generator is the electrodeless plasma excitation, enabling the generation of pure oxygen and carbon dioxide flows, which chemically destroy any electrodes as used in the RD and RB generators. In terms of flow field dimensions, the design target was a homogenous inflow onto the common European standard probe geometry. This resulted in core jet diameters of approximately $150 \mathrm{~mm}$.

The facilities were originally dedicated to the investigation of re-usable thermal protection systems (TPS). The archeated generators operate with electrodes which results in a facility-specific amount of flow field contamination by the unavoidably eroding electrode material (e.g. copper or tungsten). A particular requirement, especially for the analysis of gas-surface interaction phenomena, is a minimum contamination of the plasma jet. Any additional species in the flow adds additional collisional and chemical partners within the free flow and in interaction with the probe surface. Especially solid particles affect also the heating of the surfaces directly. In gas-surface interaction research, e.g. for the assessment of catalytic effects at the surface, these contaminants significantly corrupt the research data sets and therefore limit conclusive results. At IRS, the arc-heated generators use thermionic, i.e. hot, radiation cooled tungsten cathodes, which were thoroughly investigated previously for long-term application in electrical thrusters. The design of the magnetoplasmadynamic generators (MPG) shows low contamination at remarkably high mass-specific enthalpies. These high enthalpies are required for the correct testing of interplanetary return or meteoroid entry, which will be shown in this paper [33, 35]. Furthermore, the arc-driven generators are used with separate inlets for oxygen and nitrogen. The oxygen is injected downstream of the cathode, helping minimise the contamination. In other facilities, there is some oxygen around the cathode causing higher contamination levels. The results are low erosion rates, as illustrated in Fig. 3. In contrast, inductively coupled plasma generators (IPG) operate without electrodes, so that there is no flow contamination at all.

Various diagnostic methods have been developed to assess the plasma flow characteristics and the material behaviour when exposed to these conditions aiming to duplicate a certain entry flight scenario [4]. As the development of the facilities was mainly driven by the investigation of reusable TPS in the beginning, research in the 1990s was concentrated towards the detailed understanding of the passive to active transition of surface oxidation processes for silicon carbide based materials, the investigation of surface 


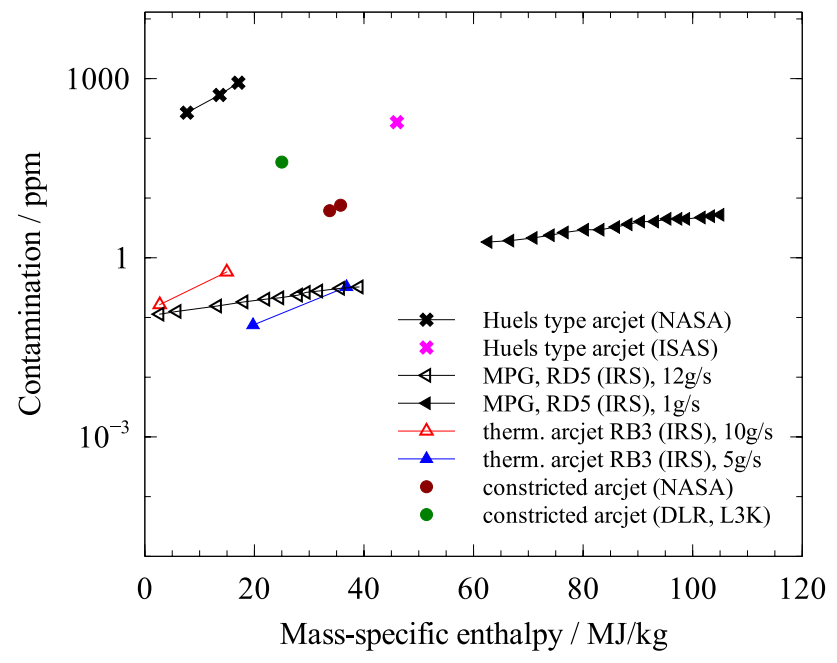

Fig. 3 Electrode contamination for different facility types for air testing (partly taken from Ref. [30] and references therein)

catalytic efficiencies and the development of surface protective layers for these materials (see Refs. [13, 26, 31]).

In the following the laboratory infrastructure is presented, followed by the presentation of the performance of the facilities based on actual experimental data sets. The data are analysed with respect to known flight trajectories in Sect. 5 .

\section{Laboratory infrastructure: power supply and vacuum pumping system}

The plasma wind tunnel laboratory infrastructure at IRS was refurbished and improved from 2013 to 2016 . The facilities are operated using a central gas supply, DC power supply and vacuum pumping system. The water cooling system is an in-house 20 bar water pressure system which is setup as a redundant system using two pumps identical in construction (type KSB WKL 65-5).

\subsection{Vacuum system}

All facilities are connected to the centralised vacuum pumping system. This system, originally installed in the late 1970s, was refurbished in 2013 to provide an advanced, explosion proof facility including a modern pressure regulation setup. Figure 4 shows a schematic of the vacuum system. Gas is extracted from the respective facility ( $P W K 1$ $P W K 4$ ) and is pumped to the outlet (named to Atmosphere). Three PFEIFFER roots pumps (RP1A-RP1C) are the first stage connected to the vacuum vessels. The parallel arrangement provides a high suction power at low pressures. A fourth roots pump (Alcatel) RP1D can be added optionally. The second stage is another roots pump (RP2). The third stage is a roughing pump stage newly installed by $\mathrm{BusCH}$ VACUum Solutions in 2013. This stage is a combination of three pumps, a roots pump (named $W V$ in Fig. 4 ) and two parallel screw vacuum pumps (named NC Pump1/Pump2 in Fig. 4). This combined stage provides the pre-vacuum required for the pumps in stages 1 and 2 to work efficiently. The upgraded pressure control system allows the pressure to be controlled from vacuum to $500 \mathrm{hPa}$. The set point is then maintained by the pumping system through a PID controller. Furthermore, the tunnels can also be run with explosive gases, e.g. hydrogen, for the investigation of entry flights to Uranus or Neptune.

The suction performance of this new system has improved slightly. The major improvements are in the advancement of the pressure control system, the achievable minimum pressure and the response time of the system to set a new pressure level. Figure 5 shows two measured data sets for the evacuation of the vessel, which takes about $700 \mathrm{~s}$ (for a volume of $7 \mathrm{~m}^{3}$ ) from ambient pressure to $<50 \mathrm{~Pa}$. The new system allows controlled ambient pressure in the vacuum vessels up to $500 \mathrm{hPa}$. The actual chamber pressure value is taken directly from the vacuum chamber pressure reading and the setpoint can be adjusted accordingly.

\subsection{Power supply}

The DC power is regulated using 6 identical current regulated thyristors each supplying $1 \mathrm{MW}$ of power. The analog control system from 1968 was updated in 2015 to a digital control system programmable for a controlled variation in power during experiments.

The power supply can deliver either high current or high voltage. Figure 6 shows the rectifier characteristic. The maximum current is $48 \mathrm{kA}$ at $125 \mathrm{~V}$. The maximum voltage is $6000 \mathrm{~V}$ at $1000 \mathrm{~A}$. The ripple of the rectifier lies below $0.5 \%$. The controlling sample rate is $3 \mathrm{~Hz}$.

\section{Facility performance}

The following subsections show the facility performance for atmospheric entry testing. The three mentioned facilities, PWK1, PWK3 and PWK4 are shown for air flow conditions. The shown performance maps are based on the European standard probe geometry which is a flat faced cylinder with a diameter of $50 \mathrm{~mm}$ and a corner radius of $11.5 \mathrm{~mm}$.

\subsection{PWK1}

PWK1 is equipped with the magnetoplasmadynamic generator RD5. This type of arcjet generator uses the electromagnetic forces induced by the arc passing through the nozzle throat resulting in further acceleration at high 
Fig. 4 Schematic of the vacuum pumping system

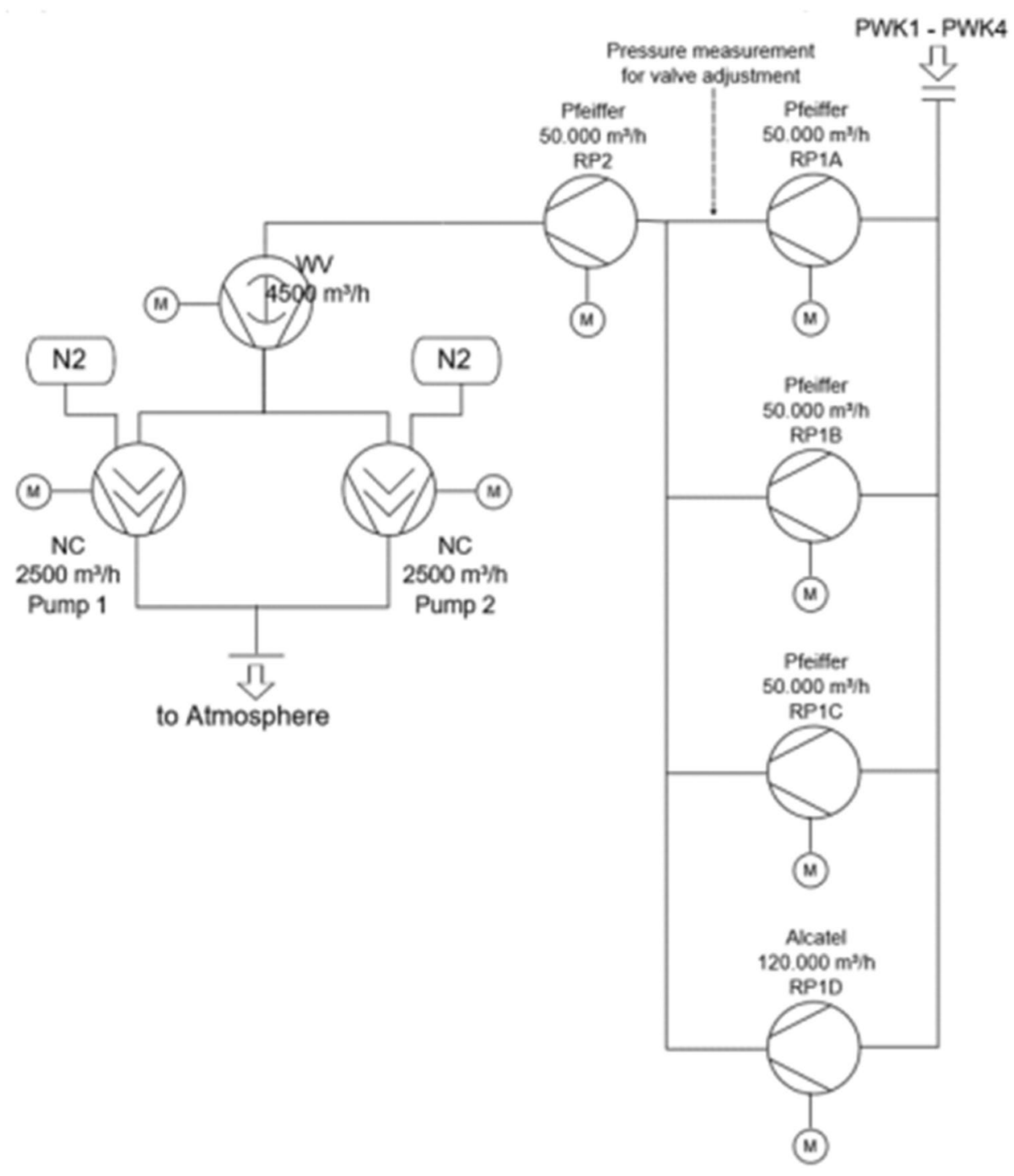

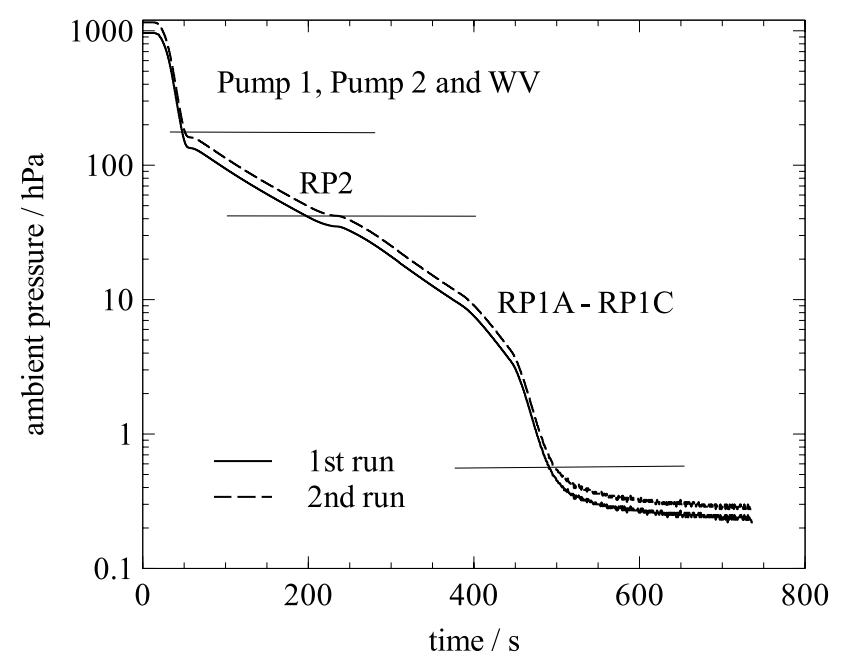

Fig. 5 Vacuum chamber pressure during evacuation (two different runs). Naming convention from Fig. 4

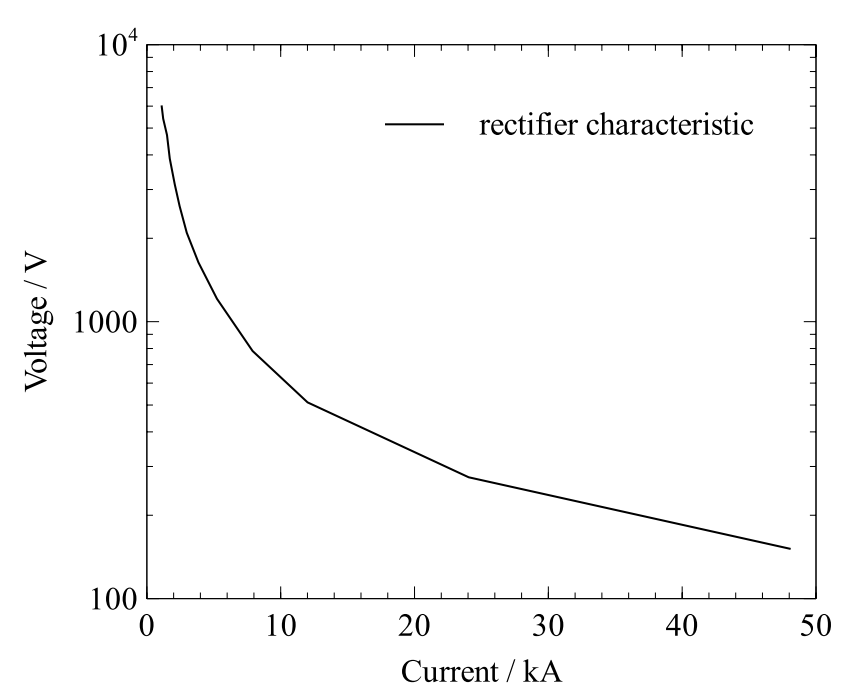

Fig. 6 Rectifier characteristics 
currents and, thus, higher enthalpies [47]. Oxygen injection downstream of the throat protects the hot cathode from oxidation. This is possible, because the arc travels through the entire nozzle and hence can energise the oxygen in the diverging section of the nozzle. The design is shown in Fig. 7, and it can be seen that the last nozzle segment acts as the anode where the arc attaches.

Figure 8 shows the measured envelope of heat flux and total pressure achieved with the facility. Some conditions have been analysed using a larger probe diameter, which is subsequently scaled to the ESA standard probe. The scaling is calculated based on the standard equations in ASTM-637 [2].The maximum heat flux measured with this facility reaches $17 \mathrm{MW} / \mathrm{m}^{2}$ at stagnation pressures of around $4.5 \mathrm{kPa}$. This maximum heat flux condition was used for a large part of the investigations of the Stardust re-entry [52].

Recent significant experimental campaigns including quantitative vacuum-ultraviolet spectroscopic measurements with ablators have been carried out in PWK1 for the analysis of the Hayabusa re-entry [25]. The flow condition chosen simulates a flight scenario of the Hayabusa capsule

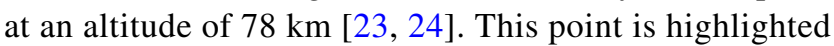
in Fig. 8 .

A further field of research which is conducted using the PWK1 facility is the investigation of space debris and demisable materials [43, 44]. An advantage here is the ability to simulate the upper Earth atmosphere where the destructive re-entry processes start. The flow field is at the limit of continuum mechanics and, therefore, quite challenging.

A new feature based on the Hayabusa testing is the possibility to simulate meteoroid entry into the Earth atmosphere [35]. A particular probe setup has been designed

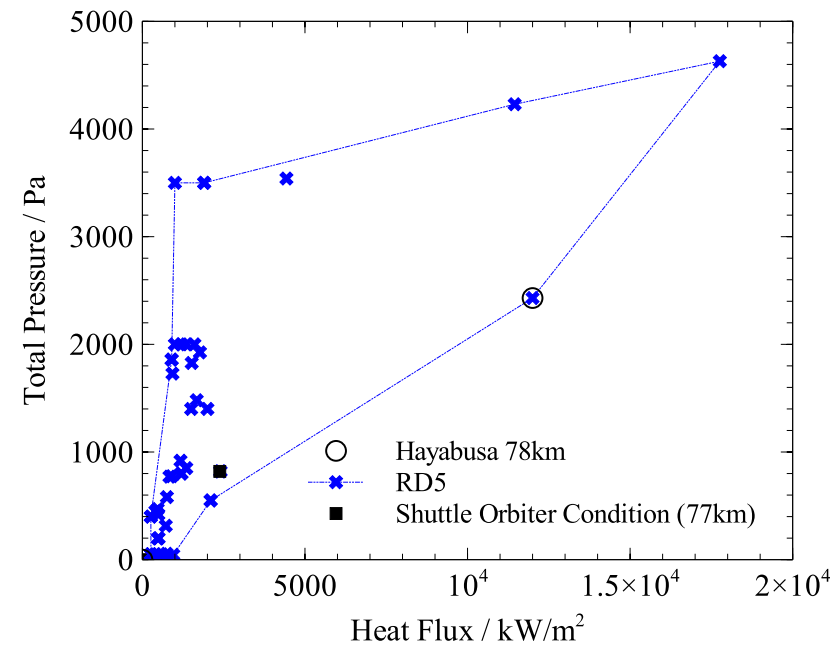

Fig. 8 Operational envelope of PWK1 based on measured air conditions

which allows the simulation of an entry scenario on ground.

\subsection{PWK4}

PWK4 is the facility using the thermal arcjet generator RB3 (see Fig. 9). Due to the higher arc chamber pressures, the maximum total pressure reaches $110 \mathrm{hPa}$. In this generator both the cathode and anode are located upstream the nozzle throat.

Figure 10 shows the available flow conditions. As can be seen, the heat flux levels are much lower compared to PWK1, but the attained total pressures are higher. The flow is supersonic reaching a maximum Mach number of approximately 5 .
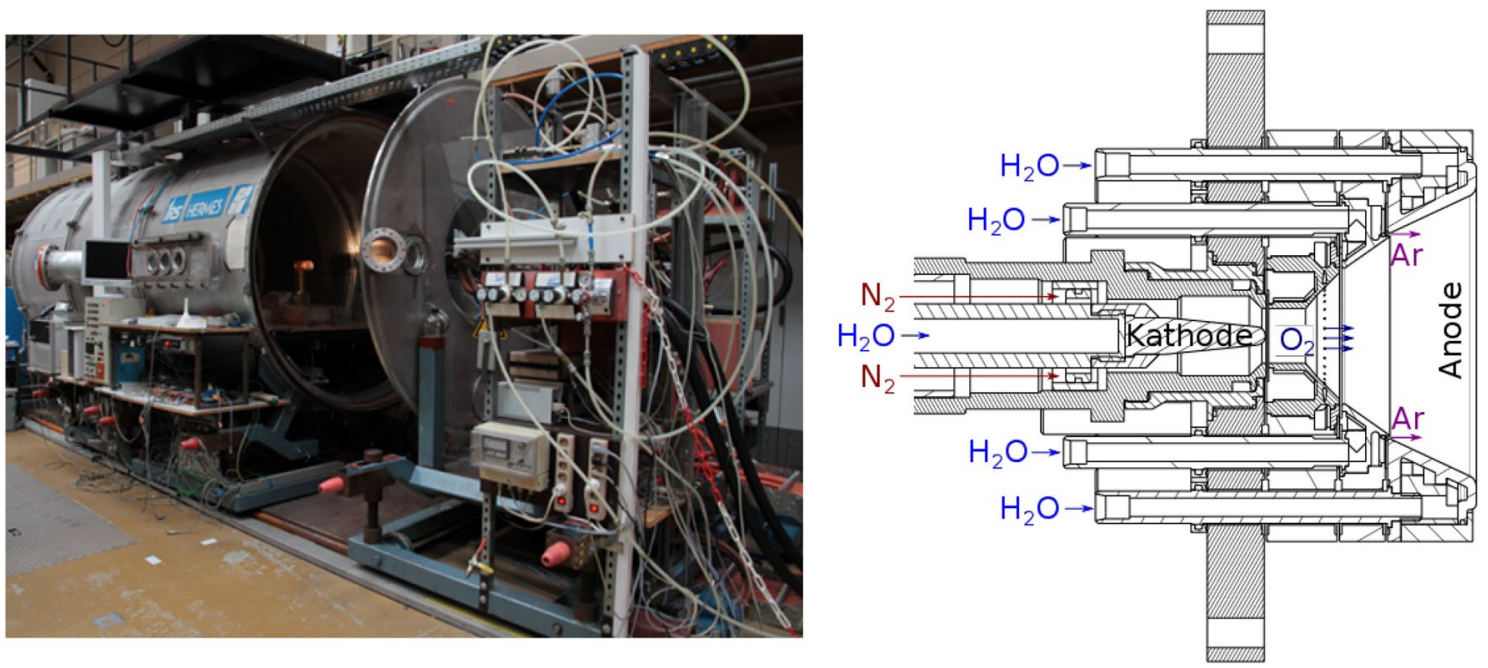

Fig. 7 PWK1 facility: photograph (left), cross section of magnetoplasmadynamic generator (right) 

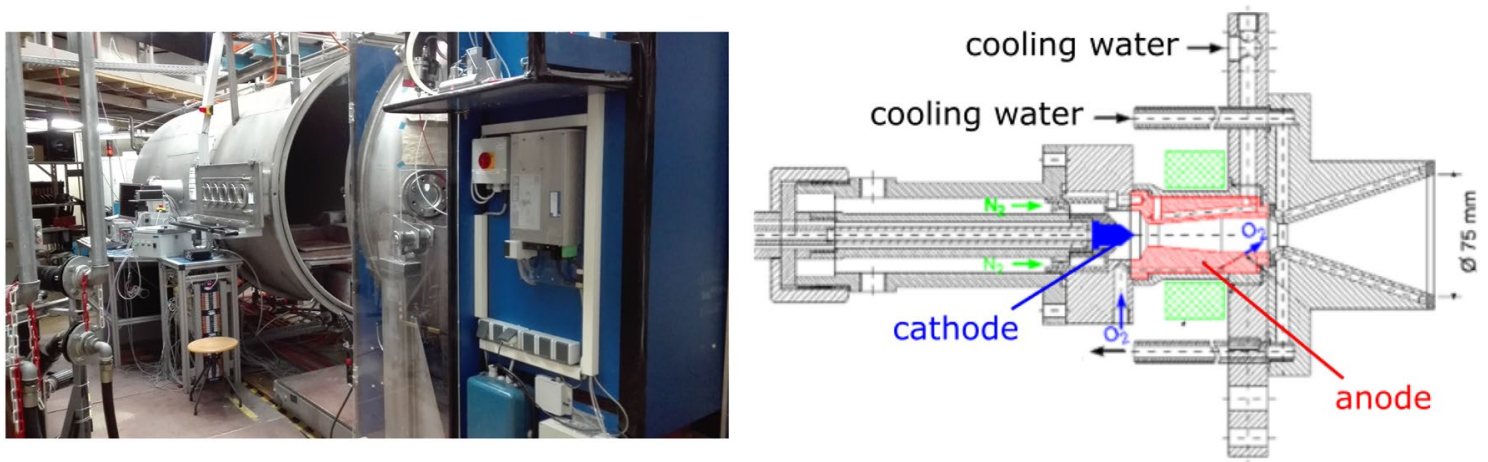

Fig. 9 PWK4 facility: photograph (left), cross section of thermal arcjet generator RB3 (right)

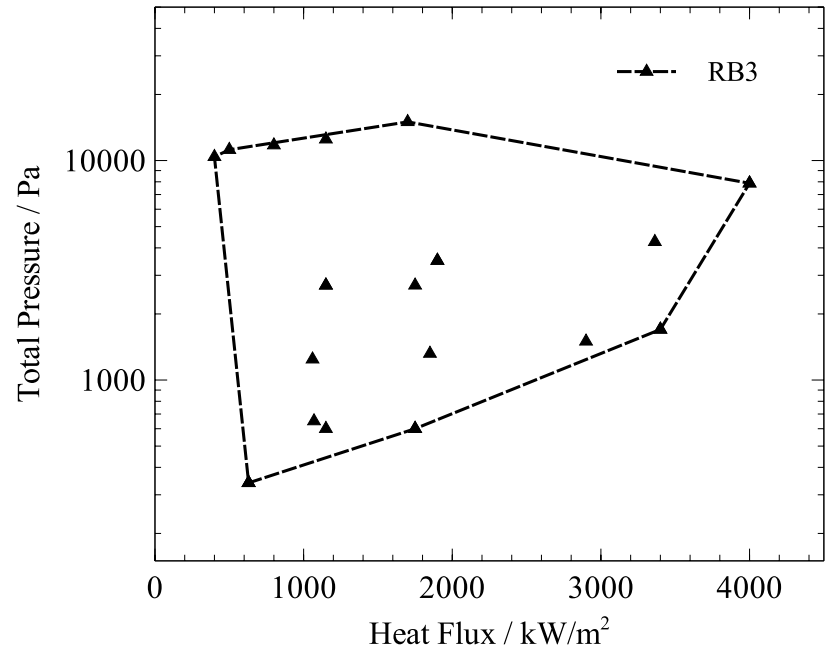

Fig. 10 Operational envelope of PWK4 based on measured air conditions

This facility is suited to test conditions close to peak heating of reusable re-entry bodies [5]. The new vacuum system now also includes an automated system for selecting high pressure conditions $(>100 \mathrm{hPa})$. Testing with controlled pressure conditions up to $500 \mathrm{hPa}$ is envisaged for the upcoming investigations of destructive re-entries and new entry system concepts where high pressure environments become essential. The by-pass system has been adapted for the higher pressures, i.e. the vessel pressure is adjusted by reducing the suction power through turning off the stages 1 and 2 and adding air into the system by variable by-pass valves.

\subsection{PWK3}

The PWK3 facility is equipped with the inductively coupled plasma (ICP) source IPG3 (inductively heated plasma generator). The plasma is generated inside a quartz tube surrounded by a coil which is part of a resonant circuit (see Fig. 11). Inside the tube, a plasma discharge is generated by particle collisions with highly accelerated free electrons. Depending on input power, gas mass flow rates, tube dimensions and operational frequency, a high-enthalpy flow exits the tube. There are designs with and without a nozzle at the tube end.

Testing at PWK3 started in the 1990s. The current design, aiming at the investigation of catalytic behaviour of thermal
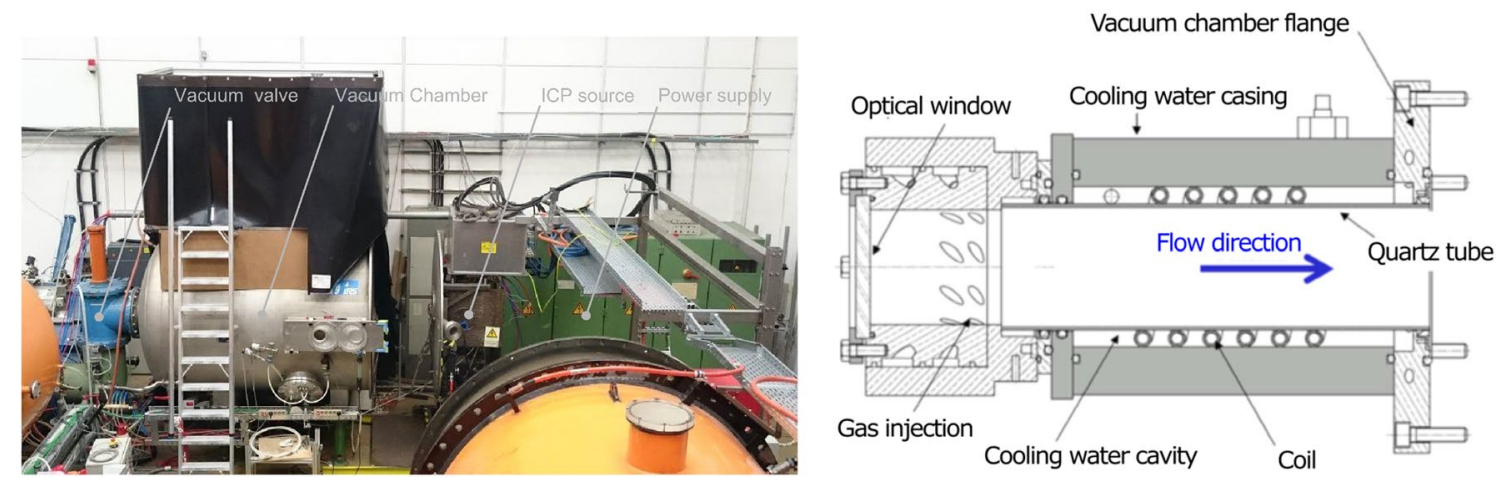

Fig. 11 PWK3 facility: Photograph (left), cross section of generator IPG4 (right) 


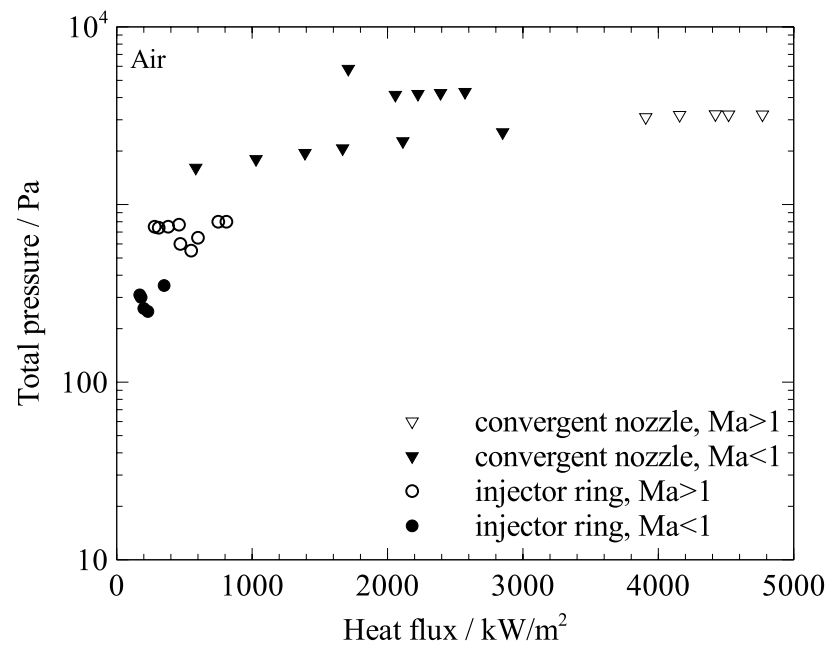

Fig. 12 PWK3 flow conditions for air

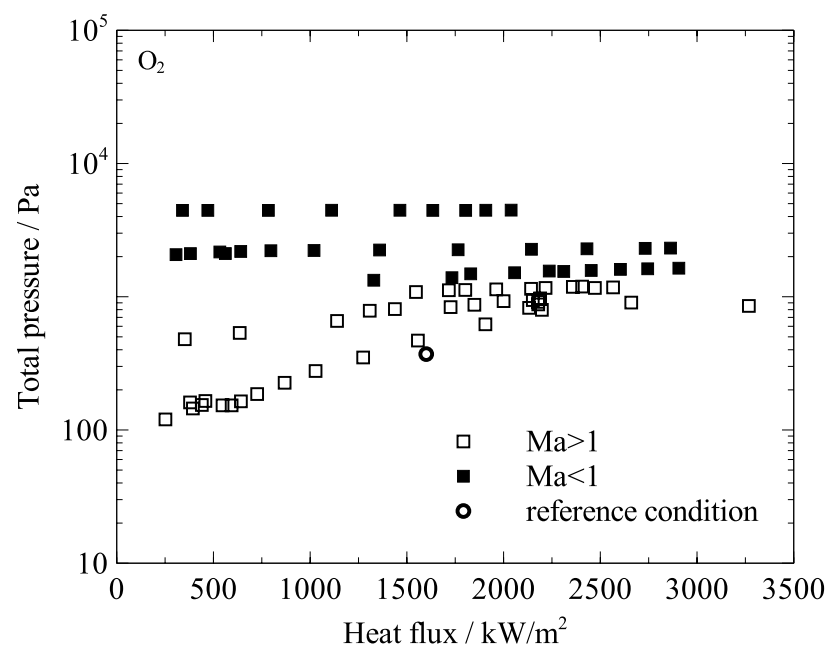

Fig. 13 PWK3 flow conditions for pure oxygen

protection systems, is an in-house development. Herdrich et al. extensively characterised the facility with particular emphasis on pure oxygen flows $[19,22]$. Due to its functional principle without electrodes, the generated plasma is free of electrode contamination, but more importantly this allows the testing and analysis of pure oxygen flows. This facility is ideally suited for fundamental surface chemistry investigations as for example catalytic behaviour of materials $[40,41,45]$. The facility is also qualified for $\mathrm{CO}_{2}$ testing [38].

The investigation of the catalytic behaviour of candidate heat shield materials is analysed mainly using pure oxygen flows $[18,39,45,50,51]$. The ability to test in pure oxygen allows decoupled investigations into the nitrogen and oxygen effects seen in air flows. Figure 12 shows the test flow conditions available for air and Fig. 13 shows the realised conditions for pure oxygen.Depending on the required pressure, enthalpy and flow velocity, the generator is equipped with a nozzle. In some cases, a so-called injector ring is required for steady tunnel operation [20]. This ring is mounted in the gas injection part to improve the inductive heating at higher gas mass flows. The heat flux levels reach values of up to $5 \mathrm{MW} / \mathrm{m}^{2}$ at the $\mathrm{kPa}$ pressure levels and is well comparable to the air flows used in PWK1 and PWK4. For some reference conditions, a full dissociation of oxygen was measured, which is of particular interest for the analysis of material behaviour.

\section{Classification of experimental conditions}

In the following, the flow conditions presented in the previous section are related to flight conditions of actual re-entry flight vehicle systems. The approach followed is the Local Heat Transfer Simulation (LHTS) concept developed by Kolesnikov [28]. The goal is to understand the ground testing conditions to match the flight scenario. The stagnation point heat flux as presented in the graphs of the previous sections, is driven by the boundary layer characteristics. The ground testing intends to rebuild the boundary layer of the flight case. This similarity is assessed based on the boundary layer equations derived for the re-entry scenario by Fay and Riddell [14]. A ground testing condition corresponds to a certain flight scenario when three essential parameters are duplicated:

$h_{\text {flight }}=h_{\text {ground }}$,

$p_{\text {tot,flight }}=p_{\text {tot,ground }}$

$\beta_{\text {flight }}=\beta_{\text {ground }}$,

where $h$ is the enthalpy and $\beta$ is the boundary layer edge velocity gradient. The index flight denotes the flight situation and ground the ground testing facility condition. To relate the measured heat flux-total pressure envelopes to flight, the data are converted into enthalpy-total pressure envelopes. This covers the requirements in Eq. (1).

The boundary layer edge velocity gradient is defined as

$\beta=\frac{\partial u}{\partial x}$.

Here, the velocity $u$ is along the surface at the boundary layer edge along the coordinate $x$, which is perpendicular to the inflow direction. The axial flow velocity is denoted $u_{\infty}$ to avoid confusion. The parameters enthalpy and total pressure are set up by adjusting the facility's input parameters (electrical input power, gas mass flow and pressure settings). The 
local mass-specific enthalpy is determined from the measured heat flux and total pressure with

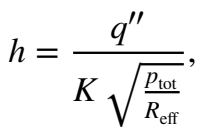

where $K$ is a gas-specific constant (for air $K=0.368 \mathrm{~kW} \mathrm{~kg}$ ) $\left.\left(\mathrm{m}^{3 / 2} \mathrm{~Pa}^{1 / 2} \mathrm{MJ}\right)\right)$, and $R_{\text {eff }}$ is the so-called effective nose radius. In this work, we used the value for $R_{\text {eff }}=2.3 \times R_{\mathrm{b}}$, where $R_{\mathrm{b}}$ denotes the body radius $[11,37]$.

This approach for the determination of the local massspecific enthalpy was published first by Zoby and Sullivan and is now stated as a standard in the ASTM E-637 [2, 54]. Independently from this approach, a probe is extensively used at IRS which allows the direct measurement of the local mass-specific enthalpy [34].

For subsonic flows, Eq. (5) requires a modification to take into account that it was derived using the modified Newtonian flow theory. This theory is not accurate for Mach numbers $\mathrm{Ma}<2$. The appropriate expression is [2]

$h=\frac{K_{\mathrm{M}} q^{\prime \prime}}{\sqrt{\frac{p_{\text {tot }}}{R_{\text {eff }}}}}\left[\frac{\left(\beta D / u_{\infty}\right)_{\text {mod.N. }} .}{\left(\beta D / u_{\infty}\right)_{x=0}}\right]^{0.5}$,

where $K_{\mathrm{M}}$ is the modified gas-specific constant (for air $\left.K_{\mathrm{M}}=2561 \mathrm{~N}^{0.5} \mathrm{~m}^{0.5} \mathrm{~s} \mathrm{~kg}^{-1}\right), D$ is the corresponding hemispherical diameter $\left(D=2 \times R_{\text {eff }}\right)$ and $u_{\infty}$ the axial freestream velocity. The boundary layer velocity gradient for the modified Newtonian flow is derived from the Mach number Ma using

$\left(\beta D / u_{\infty}\right)_{\text {mod.N. }}=\left[\frac{4\left((\gamma-1) \mathrm{Ma}^{2}+2\right)}{\gamma \mathrm{Ma}^{2}}\right]^{0.5}$.

The stagnation velocity gradient $(x=0)$ is given by

$\left(\beta D / u_{\infty}\right)_{x=0}=3-0.755 \mathrm{Ma}^{2} \quad(\mathrm{Ma}<1)$.

The (subsonic) Mach number is determined using

$\mathrm{Ma}=\left[\frac{2}{(\gamma-1)}\left(\left(\frac{p_{\text {tot }}}{p_{\mathrm{a}}}\right)^{\frac{(\gamma-1)}{\gamma}}-1\right)\right]^{0.5}$,

where $\gamma$ denotes the isentropic exponent and $p_{a}$ the ambient pressure. For the high enthalpy flows discussed here, the isentropic exponent is assumed to $\gamma=1.13$. Strictly, Eq. (9) holds only for an isentropic flow. However, the variation in the isentropic exponent results in only a small change of the Mach number. Therefore, this equation typically holds for the pressure and temperature regime in plasma wind tunnels. Experimentally determined temperature and velocity shows, that the Mach number is reasonable [53]. The ambient pressure is assumed to be equal to the background pressure in the vessel.

Figure 14 shows the local mass-specific enthalpies determined for the air flow conditions of the different facilities based on the measured data shown in Figs. 8, 10 and 13 and using the approach described with Eqs. (5)-(9). Some trajectories of flown vehicles are plotted as well. These flight data are calculated using the classical approach from Allen and Eggers [1]. Heating is calculated using the recently published data from Brandis et al. [10]. The total pressure is calculated by adding the dynamic pressure to the ambient pressure of the atmosphere as

$p_{\text {tot }}=0.5 \rho v^{2}+\rho R T$,

with the atmospheric density $\rho$ based on an exponential formulation, the gas constant $R=287 \mathrm{~J} / \mathrm{kg} / \mathrm{K}$ and the atmospheric ambient temperature taken from the MSIS database [42]. Trajectories for the Space Shuttle re-entry STS-5, the Hayabusa capsule and the Stardust capsule are plotted together with the performance of the wind tunnels in Fig. 14.

It can be seen that enthalpy and total pressure regimes covered by the IRS facilities allow a wide range of conditions for simulations of real flight scenarios from LEO entries (STS-5) to interplanetary return (Hayabusa and Stardust). To meet the third criteria, i.e. the boundary layer velocity gradient, the sample's diameter is adjusted. Thus, in conclusion, the stagnation streamline of a flight condition at a certain altitude is simulated in the ground testing facilities at IRS. Depending on altitude and flight configuration, one of the three facilities is appropriate.

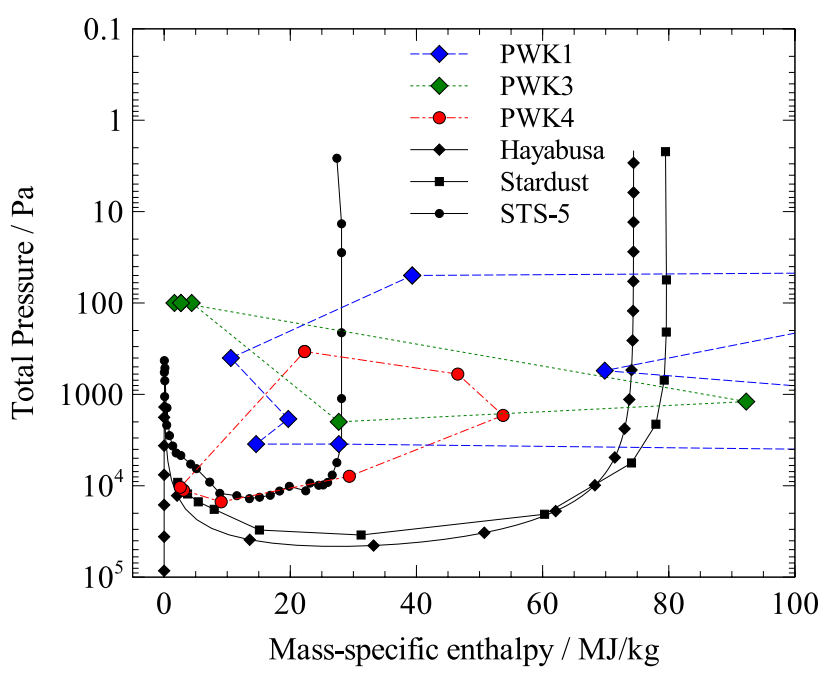

Fig. 14 Total pressure-enthalpy profile of the IRS facilities and exemplary trajectory data based on tested flow conditions and extrapolation to flight 
For entry flights from LEO with enthalpies below $30 \mathrm{MJ} /$ $\mathrm{kg}$, the three facilities cover most of the critical part of the re-entry including peak heating. For interplanetary return, the upper altitudes are covered for a wider range of possible trajectories. Although peak heating conditions are not reached, entry scenarios of interest for altitudes between 70 and $90 \mathrm{~km}$ can be reached.

\section{Conclusion}

This paper presents the latest findings for Earth entry simulations. Recent advancements in facility operation allow the rebuilding of flight situations along the whole flight trajectory. At IRS, three plasma generator principles and the corresponding facilities are used. The flow conditions available have been assessed for each facility. Recent improvements through the modernisation of the DC power supply and the vacuum pumping system show the high level of experimental flexibility. In this paper, the flow conditions are for the first time consistently translated to actual flight scenarios using the state-of-the-art flight-to-ground analogy which shows the range of possible entry scenario simulations. It is shown that the capabilities of the IRS facilities cover a wide range of conditions for the whole LEO Earth re-entry trajectory and excellent conditions for high-speed entry scenarios at altitudes above $70 \mathrm{~km}$.

Acknowledgements This work relates to a huge amount of work of former researchers of IRS. The authors would like to thank all colleagues at IRS for supporting this work. Furthermore, the authors thank the colleagues from the department VI of the University of Stuttgart for their continuous support in maintaining the systems. The help from the mechanical and electronics workshop is gratefully acknowledged.

Funding Open Access funding enabled and organized by Projekt DEAL.

\section{Declarations}

Conflict of interest The authors declare that they have no conflicts of interest.

Open Access This article is licensed under a Creative Commons Attribution 4.0 International License, which permits use, sharing, adaptation, distribution and reproduction in any medium or format, as long as you give appropriate credit to the original author(s) and the source, provide a link to the Creative Commons licence, and indicate if changes were made. The images or other third party material in this article are included in the article's Creative Commons licence, unless indicated otherwise in a credit line to the material. If material is not included in the article's Creative Commons licence and your intended use is not permitted by statutory regulation or exceeds the permitted use, you will need to obtain permission directly from the copyright holder. To view a copy of this licence, visit http://creativecommons.org/licenses/by/4.0/.

\section{References}

1. Allan, H.J., Eggers, A.J.: A study of the motion and aerodynamic heating of ballistic missiles entering the Earth's atmosphere at high supersonic speeds. Tech. Rep. NACA Technical Report 1381, Forty-Fourth Annual Report of the NACA-1958, Washington, D.C. (1958)

2. ASTM International. Standard test method for calculation of stagnation enthalpy from heat transfer theory and experimental measurements of stagnation-point heat transfer and pressure. Tech. Rep. E637-05 (2005)

3. Auweter-Kurtz, M., Epple, J., Kurtz, H., Loesener, O., Messerschmid, E.W., Mulzer, D.: Arc heated high enthalpy channel for thermal protection systems of spacecrafts. In: Proceedings of the 4th International Symposium on Spacecraft Materials in Space Environment (1988). (ISBN 285428228)

4. Auweter-Kurtz, M., Fertig, M., Herdrich, G., Hirsch, K., Loehle, S., Pidan, S., Schumacher, U., Winter, M.: Characterization of High-Enthalpy Flows, Chap. 4.7, pp. 200-220. Wiley-VCH, Weinheim (2005). (ISBN 3-527-27735-8)

5. Auweter-Kurtz, M., Fertig, M., Herdrich, G., Laux, T., Schöttle, U., Wegmann, T., Winter, M.: Entry experiments at IRS-inflight measurement during atmospheric entries. In: 53rd International Astronautical Congress, IAC-02-V.6/I.7.03, Houston, TX (2002)

6. Auweter-Kurtz, M., Habiger, H., Laure, S., Messerschmid, E.W., Schönemann, A.: Experimental investigations of MPD devices used as reentry test plasma sources. In: AIAA/DGLR/JSASS 21st International Electric Propulsion Conference, Orlando, FL, 1990, vol. 90-2569. AIAA (1990). 10.2514/6.1990-2569

7. Auweter-Kurtz, M., Herdrich, G., Laure, S., Wagner, H.P.: Plasma source development for technical applications at IRS. Vacuum 73(3-4), 309-316 (2004). https://doi.org/10.1016/j. vacuum.2003.12.077

8. Auweter-Kurtz, M., Kurtz, H., Laure, S.: Plasma generators for re-entry simulation. J. Propuls. Power 12(6), 1053-1061 (1996). https://doi.org/10.2514/3.24143

9. Balboni, J., Gökçen, T., Hui, F., Graube, P., Morrissey, P., Lewis, R.: Consolidating NASA's arc-jet. In: 45th AIAA Thermophysics Conference. American Institute of Aeronautics and Astronautics (2015).https://doi.org/10.2514/6.2015-2667

10. Brandis, A.M., Johnston, C.O.: Characterization of stagnationpoint heat flux for Earth entry. In: 45th AIAA Plasmadynamics and Lasers Conference. Atlanta, GA (2014). https://doi.org/10. 2514/6.2014-2374

11. Brown, R.D.: A comparison of the theoretical and experimental stagnation-point heat transfer in an arc-heated subsonic stream. Tech. Rep. NASA TN D-1927, NASA Langley Research Center (1964)

12. Cushman, G., Alunni, A., Balboni, J., Zell, P., Hartmann, J., Empey, D.M.: The laser enhanced arc-jet facility (LEAF-Lite): Simulating convective and radiative heating with arc-jets and multiple 50-kW CW lasers. In: AIAA Aviation 2018. AIAA (2018). https://doi.org/10.2514/6.2018-3273

13. Dabalà, P., Hilfer, G., Auweter-Kurtz, M.: Investigation of the oxidation behaviour of thermal protection materials supported by mass spectrometry. In: 2nd European Symposium on Aerothermodynamics for Space Vehicles, pp. 237-246 (1994)

14. Fay, J.A., Riddell, F.R.: Theory of stagnation point heat transfer in dissociated air. AIAA J. 25(2), 373-386 (1958). https://doi. org/10.2514/8.7517

15. Gülhan, A., Esser, B., del Vecchio, A., Loehle, S., Sauvage, N., Chazot, O., Asma, C.O.: Comparative heat flux measurements 
on standard models in plasma facilities. In: 13th International Space Planes and Hypersonic Systems and Technologies, AIAA-2005-3324. AIAA (2005)

16. Gupta, R.N.: Aerothermodynamic analysis of Stardust sample return capsule with coupled radiation and ablation. J. Spacecr. Rockets 37(4), 507-514 (2000). https://doi.org/10.2514/2.3592

17. Herdrich, G., Auweter-Kurtz, M., Endlich, P.: Mars entry simulation using the inductively heated plasma generator IPG4. J. Spacecr. Rockets 40(5), 690-694 (2003). https://doi.org/10. 2514/6.2001-3013

18. Herdrich, G., Auweter-Kurtz, M., Fertig, M., Loehle, S., Pidan, S., Winter, M.: Present design of the flight instrumentations pyrex, phlux and respect for the capsule Expert. In: D. Danesy (ed.) Fifth European Symposium on Aerothermodynamics for Space Vehicles, ESA Special Publication, vol. 563, pp. 401-407 (2005)

19. Herdrich, G., Auweter-Kurtz, M., Kurtz, H.: New inductively heated plasma source for reentry simulations. J. Thermophys. Heat Transf. 14(2), 244-249 (2000). https://doi.org/10.2514/2. 6515

20. Herdrich, G., Auweter-Kurtz, M., Kurtz, H., Laux, T., Schreiber, E.: Investigation of the inductively heated plasmagenerator IPG3 using injection rings of different geometries. In: 21st Aerodynamic Measurement Technology and Ground Testing Conference. American Institute of Aeronautics and Astronautics (2000). 10.2514/6.2000-2445

21. Herdrich, G., Dropmann, M., Marynowski, T., Loehle, S., Fasoulas, S.: Atmospheric entry simulation capabilities of the IRS plasma wind tunnel PWK3 for Mars and Venus. In: 7th International Planetary Probe Workshop 2010. IPPW, Barcelona, Spain (2010)

22. Herdrich, G., Petkow, D.: High enthalpy, water-cooled and thinwalled icp sources: Characterization and mhd-optimization. J. Plasma Phys. 74(3), 391-429 (2008). https://doi.org/10.1017/ S0022377807006927

23. Hermann, T., Loehle, S., Fasoulas, S., Leyland, P., Marraffa, L., Bouilly, J.M.: Influence of ablation on vacuum-ultraviolet radiation in a plasma wind tunnel flow. J. Thermophys. Heat Transf. (2017). https://doi.org/10.2514/1.T4936

24. Hermann, T., Loehle, S., Leyland, P., Marraffa, L., Bouilly, J.M., Fasoulas, S.: First results on ablation radiation coupling through optical emission spectroscopy from the vacuum ultraviolet to the visible. In: 8th European Symposium on Aerothermodynamics for Space Vehicles. Lisbon, Portugal (2015)

25. Hermann, T., Loehle, S., Zander, F., Fulge, H., Fasoulas, S.: Characterization of a re-entry plasma wind tunnel flow with vacuum ultraviolet to near infrared spectroscopy. J. Thermophys. Heat Transf. 30(3), 673-688 (2016). https://doi.org/10.2514/1.T4695

26. Hilfer, G., Auweter-Kurtz, M.: Experimental and theoretical investigation of the oxidation behaviour of thermal protection materials under oxygen attack. High Temp. High Press. 27(28), 435-448 (1995)

27. Hong, B.G., Kang, B.R., Choi, J.C., Oh, P.Y.: Characteristics of a plasma wind tunnel for the development of thermal protection materials. Aeronaut. J. 121(1240), 821-834 (2017). https://doi. org/10.1017/aer.2017.35

28. Kolesnikov, A.F.: Extrapolation from high enthalpy tests to flight based on the concept of local heat transfer simulation. In: Measurement Techniques for High Enthalpy and Plasma Flows, 8B. VKI, RTO-Research and Technology Organization, RhodeSaint-Genese, Belgium (1999). (ISBN 92-837-1030-4)

29. Laub, B., Venkatapathy, E.: Thermal protection system technology and facility needs for demanding future planetary missions. In: A. Wilson (ed.) Planetary Probe Atmospheric Entry and Descent Trajectory Analysis and Science, ESA Special Publication, vol. 544, pp. 239-247. ESA Publication Division (2004). http://artic
les.adsabs.harvard.edu/cgi-bin/nph-iarticle_query?2004ESASP. 544..239L\&data_type $=$ PDF_HIGH\&whole_paper $=$ YES\&type $=$ PRINTER\&filetype $=$.pdf

30. Laure, S., Auweter-Kurtz, M., Fasoulas, S., Habiger, H., Röck, W.: The irs plasma wind tunnels as a tool for the investigation of planet entry missions. In: 17th AIAA Aerospace Ground Testing Conference, AIAA 92-3886. AIAA (1992)

31. Laux, T., Feigl, M., Auweter-Kurtz, M., Stöckle, T.: Estimation of the surface catalycity of PVD coatings by simultaneous heat flux and LIF measurements in high enthalpy air flows. In: 34th Thermophysics Conference, AIAA-2000-2364. AIAA (2000).https:// doi.org/10.2514/6.2000-2364

32. Loehle, S.: Review of heat flux measurements for high enthalpy flows. In: 32nd AIAA Aerodynamic Measurement Technology and Ground Testing Conference. AIAA (2016).https://doi.org/10. 2514/6.2016-3205

33. Loehle, S., Brandis, A., Hermann, T., Peter, J.: Numerical investigation of the re-entry flight of Hayabusa and comparison to flight and ground testing data. In: 43rd AIAA Thermophysics Conference. AIAA, New Orleans, LA (2012). https://doi.org/10.2514/6. 2012-3102

34. Loehle, S., Steinbeck, A., Fasoulas, S.: Local mass-specific enthalpy measurements with a new mass injection probe. J. Thermophys. Heat Transf. 30(2), 301-307 (2016). https://doi. org/10.2514/1.t4709

35. Loehle, S., Zander, F., Hermann, T., Eberhart, M., Meindl, A., Oefele, R., Vaubaillon, J., Colas, F., Vernazza, P., Drouard, A., Gattacceca, J.: Experimental simulation of meteorite ablation during Earth entry using a plasma wind tunnel. Astrophys. J. 837, 2 (2017). https://doi.org/10.3847/1538-4357/aa5cb5

36. Lu, F.K., Marren, D.E. (eds.): Advanced Hypersonic Test Facilities, Progress in Astronautics and Aeronautics, vol. 198. AIAA, Reston, VA (2002). (ISBN 1-56347-541-3)

37. Marvin, J.G., Pope, R.B.: Laminar convective heating and ablation in the mars atmosphere. AIAA J. 5, 240-248 (1967)

38. Marynowski, T., Loehle, S., Fasoulas, S.: Two-photon absorption laser-induced fluorescence investigation of $\mathrm{CO} 2$ plasmas for Mars entry. AIAA J. Thermophys. Heat Transf. (2014). https://doi.org/10.2514/1.T4223

39. Massuti-Ballester, B., Herdrich, G.: Gas-surface interaction. experimental determination of PM1000 and CVD-C/SiC catalytic properties. In: 8th European Symposium on Aerothermodynamics for Space Vehicles (2015)

40. Massuti-Ballester, B., Herdrich, G., Friess, M.: Oxidation of PM1000 and C/C-SiC exposed to highly dissociated oxygen and nitrogen flows. J. Eur. Ceram. Soc. 40(6), 2306-2316 (2020). https://doi.org/10.1016/j.jeurceramsoc.2020.01.053

41. Massuti-Ballester, B., Pidan, S., Herdrich, G., Fertig, M.: Recent catalysis measurements at IRS. Adv. Sp. Res. 56(4), 742-765 (2015). https://doi.org/10.1016/j.asr.2015.04.028

42. NASA: MSIS-E-90 Atmosphere Model (2013). http://omniweb. gsfc.nasa.gov/vitmo/msis_vitmo.html

43. Pagan, A.S., Massuti-Ballester, B., Herdrich, G.: Experimental thermal response and demisability investigations on five aerospace structure materials under simulated destructive re-entry conditions. In: 46th Aerodynamic Measurement Technology and Ground Testing Conference. AIAA, Washington, D.C. (2016)

44. Pagan, A.S., Massuti-Ballester, B., Herdrich, G., Merrifield, J.A., Beck, J.C., Liedtke, V., Ogawa, R., Kubota, Y., Hatta, H., Bonvoisin, B.: Overview of recent experimental activities towards the characterization of demisable materials at IRS. In: 8th European Workshop on TPS and Hot Structures (2016)

45. Pidan, S., Auweter-Kurtz, M., Fertig, M., Herdrich, G., Laux, T., Trabandt, U.: Catalytic behaviour of candidate thermal protection materials. In: D. Danesy (ed.) Fifth European Symposium 
on Aerothermodynamics for Space Vehicles, ESA Special Publication, vol. 563, pp. 95 (2005)

46. Purpura, C., Filippis, F.D., Graps, E., Trifoni, E., Savino, R.: The GHIBLI plasma wind tunnel: Description of the new CIRAPWT facility. Acta Astronaut. 61(1-6), 331-340 (2007). https:// doi.org/10.1016/j.actaastro.2007.01.046

47. Schrade, H.O., Auweter-Kurtz, M., Kurtz, H.L.: Cathode erosion studies on MPD thrusters. In: AIAA/DGLR/JSASS 18th International Electric Propulsion Conference, Alexandria, VA (1985)

48. Sepka, S., Gasch, M., Beck, R.A., White, S.: Testing of candidate rigid heat shield materials at LHMEL for the entry, descent, and landing technology development project. In: Advanced Ceramic Coatings and Materials for Extreme Environments II, pp. 127-155. Wiley, Inc. (2012). https://doi.org/10.1002/97811 18217474.ch11

49. Smith, R.K., Wagner, D.A., Cunningham, J.A.: A survey of current and future plasma arc-heated test facilities for aerospace and commercial applications. In: 36th Aerospace Sciences Meeting and Exhibit. AIAA (1997).https://doi.org/10.2514/6. 1998-146

50. Steinbeck, A., Fertig, M., Herdrich, G., Röser, H.P.: Enhanced evaluation of recombination coefficient measurements in plasma wind tunnels. In: 41st AIAA Thermophysics Conference, AIAA 2009-3933 (2009). https://doi.org/10.2514/6.2009-3933

51. Steinbeck, A., Lein, S., Herdrich, G., Röser, H.P., Hollandt, J., Gutschwager, B.: Die Sensorsysteme PYREX. PHLUX und RESPECT auf der Wiedereintrittskapsel EXPERT. Physikalisch Technische Bundesanstalt, Braunschweig und Berlin (2009)

52. Wernitz, R., Fertig, M., Herdrich, G., Loehle, S., Winter, M., Röser, H.P.: Assessment of PWT conditions for the STARDUST post-flight evaluation. In: 7th International Planetary Probe Workshop. Atlanta, GA (2008)

53. Zander, F., Loehle, S., Hermann, T., Fulge, H.: Fabry-perot spectroscopy for kinetic temperature and velocity measurements of a high enthalpy air plasma flow. J Appl Phys D (2017). https://doi. org/10.1088/1361-6463/aa7b0c

54. Zoby, E.V.: Empirical stagnation-point heat-transfer relation in several gas mixtures at high enthalpy levels. NASA Technical Note (TN D-4799) (1968)

Publisher's Note Springer Nature remains neutral with regard to jurisdictional claims in published maps and institutional affiliations. 